\title{
A INCLUSÃO DO ALUNO COM SURDEZ NA INSTITUIÇÃO ESCOLAR
}

\author{
Lucimara Destéfani de Souza PENHA ${ }^{1}$ \\ Luciene Destéfani de Souza SILVA ${ }^{2}$ \\ Carla Maria Nogueira de CARVALHO
}

\begin{abstract}
${ }^{1}$ Doutoranda em Ciências da Educação (U.N.R), Especialista em Processos de Ensino-Aprendizagem em Língua Portuguesa, Coordenadora Pedagógica na Rede de Ensino de Três Corações. E-mail:destefanimg@yahoo.com.br ${ }^{2}$ Doutoranda em Ciências da Educação (U.N.R), Especialista em Metodologia do Ensino, Coordenadora Pedagógica na Rede de Ensino de Três Corações. E-mail: destefanilu2@gmail.com

${ }^{3}$ Doutoranda em Ciências da Educação (U.N.R), Mestre em Educação (UNINCOR), Especialista em Metodologia do Ensino, Docente na Universidade Vale do Rio Verde (UNINCOR) e na Universidade do Estado de Minas Gerais (UEMG). E-mail: profcarlamaria@oi.com.br
\end{abstract}

\section{Recebido em: 20/05/2014 - Aprovado em: 30/06/2014 - Disponibilizado em: 30/07/2014}

RESUMO: Diante do cenário atual da Educação, a inclusão de alunos com deficiência está se tornando frequente no ambiente escolar regular. Dentre esses alunos, o presente trabalho abordou o contexto dos discentes surdos. Assim, através de pesquisa bibliográfica, buscou-se refletir sobre os desafios da "inclusão do aluno com surdez na instituição escolar", perpassando pelo contexto histórico, legal, da formação de professores e da educação bilingue. Não basta que o indivíduo esteja na escola é preciso que lhe sejam oferecidas oportunidades de construir seu saber, sua identidade e sua cultura para que não seja apenas alguém adaptado à sociedade, mas sim sujeito construtor de si mesmo e partícipe da sociedade em que vive.

Palavras-chave: Inclusão; Surdez; Libras; Bilinguismo; Ensino Regular.

\begin{abstract}
Given the current scenario of Education, the inclusion of students with disabilities is becoming frequent in the regular school environment.Among these students, the present work approached the context of deaf students. Therefore, through a bibliographic research, was sought to reflect about the challenges of the "inclusion of students with deafness in the school institution", traversing the historical context, the legal context,the teacher training and the bilingual education.It is not enough the presence of the individual at the school.It is necessary that opportunities are being offered, to build his knowledge, his identity, his culture,to turn him not just in someone adapted to the society,but into a constructor of himself who will participate of the society around him.
\end{abstract}

Key-words: Inclusion,Deafness,Libras,Bilingualism, Regular Teaching

\section{INTRODUÇÃO}

A educação escolar dos alunos com deficiência tem sido objeto de estudos, discussões e controvérsias ao longo dos anos.

Atualmente os alunos deficientes têm acesso à escola sob três tipos: segregação (instituições públicas ou privadas nas quais estes são atendidos), sala de recursos (complementa o processo pedagógico das classes comuns) e na escola regular (escola inclusiva).
A escola de ensino regular passou a receber estes alunos após a Constituição de 1988 legislar que estes deverão ser atendidos nesta (BRASIL/1988). Também a Declaração de Salamanca (BRASIL/1994) considera a

“escola regular, com orientação inclusiva, possui os meios mais eficazes contra a discriminação e constrói comunidades acolhedoras e uma sociedade inclusiva e para todos”.

Sendo assim, através da Constituição Federal de 1988 e da Lei de Diretrizes e Bases 
da Educação Nacional, em seu artigo 58, o Brasil assumiu o compromisso de construir um sistema educacional inclusivo e para todos desde os primeiros anos escolares até as universidades.

Assim, o presente estudo buscou refletir sobre os desafios e possibilidades presentes na inclusão do aluno surdo na escola regular, visto que a presença de alunos deficientes começa a ser frequente no ambiente escolar, cabendo aos docentes oportunizar práticas de ensino que visem uma educação de qualidade e um ambiente favorável à educação para todos.

\section{2 - DA HISTÓRIA A ATUALIDADE}

Segundo Goldfeld (1997) e Skliar (2005), são poucos os dados históricos sobre a surdez e a educação dos surdos nas civilizações antigas, pois os registros desta aparecem somente no início do século XVI. No entanto, durante o processo educacional dos surdos existiram três abordagens educacionais distintas: Oralismo, Comunicação total e Bilinguismo.

Pesquisas que beneficiariam o desenvolvimento do pensamento do surdo com a utilização de uma linguagem própria e natural (língua de sinais) somente ocorreriam no séc. XVI. Segundo Lacerda (1998), neste período, o objetivo da educação dos surdos era favorecer o desenvolvimento do pensamento, para adquirir um conhecimento e depois se comunicar com o mundo ouvinte. Era frequente, naquela época, não divulgar como se conduzia a educação de surdos, bem como não era comum as trocas de experiências. Assim, torna-se difícil saber como era conduzida a educação dos surdos, pois muitos trabalhos desenvolvidos foram esquecidos e/ou se perderam no tempo.

No século XVIII, segundo relato de Reily (2007) e Thoma (2006), acreditava-se ser viável reunir pessoas surdas em instituições totalitárias, o que possibilitaria um poder disciplinatório tornando esses "animais" seres dóceis e passivos no contexto social.

Em 1816, Thomas Hopkins Gallaudet visita L'Epée para aprender Sinais e os Sinais Metódicos, tendo como instrutor Laurent Clerc. Eles implantaram nos Estados Unidos a primeira escola para surdos a American School for the Deaf.

Em 1964 o Congresso Americano autoriza o funcionamento da primeira faculdade para surdos, localizada em Washington, a National Deaf-Mute College (Universidade Nacional para Surdos-Mudos) atualmente conhecida como Universidade de Gallaudet, sendo a única instituição de estudos superiores do mundo exclusiva para pessoas surdas. Esta faculdade foi fundada por Edward Gallaudet, filho de Thomas Gallaudet (MOURA, 2000).

Já no Brasil segundo Barbosa (2010) a pedido de Dom Pedro II, o professor Ernest Huet, foi convocado para trabalhar no Imperial Instituto de Meninos Surdos, que 
hoje se denomina Instituto Nacional de Educação de Surdos - INES, desta forma Huet foi um dos grandes responsáveis pela formação da Língua Brasileira de Sinais (Libras), por meio do "método combinado", criado por L’Epée.

No final do século XIX, precisamente em 1880, o Congresso de Milão, decidiu que todo sistema educacional deveria utilizar o método oralista para a educação de pessoas surdas, por considerar que este era o mais adequado. Tal decisão visava extinguir as práticas gestuais.

Segundo Goldfeld (1997) este método tinha a finalidade de minimizar a "deficiência", e/ou saná-la, visto que a surdez era vista como uma doença que deveria ser erradicada, independente de quais alternativas fossem utilizados (prótese auditiva, métodos e atitudes pedagógicas etc.).

Em meados do século XX, conforme Ferreira e Guimarães (2006), surgem os movimentos de integração ${ }^{1}$ e normalização ${ }^{2}$,

\footnotetext{
1 De acordo com a Política Nacional de Educação Especial/SEESP/MEC (1994, p.18), integração é "Um processo dinâmico de participação das pessoas num contexto relacional, legitimando sua interação nos grupos sociais. A integração implica reciprocidade." A referida Política também se refere à integração escolar como sendo um "Processo gradual e dinâmico que pode tomar distintas formas de acordo com as necessidade e habilidades dos alunos. A integração educativa-escolar refere-se ao processo de educarensinar, no mesmo grupo, a crianças com e sem necessidades educativas especiais, durante uma parte ou na totalidade do tempo de permanência na escola."
}

2 A Política Nacional de Educação Especial/SEESP/MEC (1994, p.22), refere-se à normalização como sendo "Um princípio que representa a base filosófico-ideológica da integração. Não se trata de normalizar as pessoas, mas sim o introduzidos na Dinamarca na década de 1960, que reconhecia as potencialidades dos indivíduos com deficiência. A filosofia da normalização era oportunizar ao indivíduo com deficiência condições de vida mais parecida com a do individuo sem deficiência. A ideia inicial era “(...) normalizar estilos ou padrões de vida", e não tornar normais as pessoas com deficiência. No entanto, houve esse equívoco e o movimento de integração atuou com a idéia de que todos deveriam ter direitos, recursos e tratamentos iguais, o que acabou incorrendo um erro, uma vez que os indivíduos são diferentes uns dos outros.

Evidencia-se, então, que ao longo da história, os indivíduos com deficiência sempre estiveram à margem da sociedade e, consequentemente, do sistema de ensino denominado regular. Hoje, com as perspectivas da educação inclusiva, preocupa ainda o fato de que não basta incluir pela garantia da matrícula na escola. É necessário que se pense na singularidade de cada aluno surdo e como serão atendidas suas necessidades educacionais por parte dos professores e demais profissionais da educação.

\section{3- NOVOS CAMINHOS ATRAVÉS DA EDUCAÇÃO BILÍNGUE}

As restrições na organização de projetos políticos de cidadania, dos direitos

contexto em que se desenvolvem, ou seja, oferecer, aos portadores de necessidades especiais modos e condições de vida diária o mais semelhantes possível às formas e condições de vida do resto da sociedade." 
linguísticos e as dificuldades no processo de reorganização e de reconstruções pedagógicas das pessoas com surdez, bem como nos modelos de educação bilíngue ${ }^{3}$ e bicultural $^{4}$ resultam ainda na existência de conflitos. Skliar (2001). Conflitos estes, que a Lei de Diretrizes e Bases da Educação Nacional, lei $\mathrm{n}^{\circ}$ 9.394/96 (LDBEN/96) buscou amenizar assegurando aos alunos que necessitam da educação especial “currículos, métodos, técnicas, recursos educativos e organização específicos, para atender às suas necessidades;"

O decreto $n^{\circ} 5.626$, de 22 de dezembro de 2005, regulamentou a Lei $\mathrm{n}^{\circ} 10.436$, de 24 de abril de 2002, e o art. 18 da Lei $n^{0} 10.098$, de 19 de dezembro de 2000, que em seu capítulo II expõe:

"a Libras deve ser inserida
como disciplina curricular
obrigatória nos cursos de
formação de professores para
o exercício do magistério, em
nível médio e superior, e nos
cursos de Fonoaudiologia, de
instituições de ensino, públicas
e privadas, do sistema federal
de ensino e dos sistemas de

\footnotetext{
${ }^{3}$ Goldfeld (1997, p.44) conceitua a educação bilíngüe, como sendo "[...] a aquisição da língua materna pelo surdo, língua de sinais, que é considerada a língua natural dos surdos e, como segunda língua, a língua oficial escrita de seu país, no caso do Brasil a língua portuguesa."

${ }^{4}$ Já a educação bicultural é entendida neste estudo como a prevalência de duas culturas em um mesmo contexto educacional, isto é: a cultura surda e a cultura ouvinte.
}

ensino dos Estados, do Distrito Federal e dos Municípios.”

Ou seja, esta lei define como deve ser a formação dos profissionais para atuarem junto aos alunos surdos, da mesma forma que visa uma educação bilíngue para estes.

O capítulo III aponta:

"a formação de docentes para o ensino de Libras nas séries finais do ensino fundamental, no ensino médio e na educação superior deve ser realizada em nível superior, em curso de graduação de licenciatura plena em Letras: Libras ou em Letras: $\quad$ Libras/Língua Portuguesa como segunda língua.”

Explicita ainda que as pessoas surdas terão prioridade para formação nestes cursos.

No que tange a realidade, essa cisão entre as características dos alunos surdos e a dos discentes ouvintes, deficientes ou não, traz uma carga histórica de lutas, visto que o bilinguismo, agora como direito legal e linguístico, é uma conquista inigualável à sociedade surda corroborando para uma inclusão social mais efetiva no mundo dos ouvintes. Assim o bilinguismo torna-se uma área específica do saber.

Oportunizar um ambiente favorável à aquisição natural da língua de sinais em conjunto com a formação de profissionais 
habilitados para interagirem com esses alunos, ainda é um desafio na educação de surdos.

Além da participação e dos direitos assegurados por lei, a presença do educador surdo, é um meio que oportuniza a construção de novos caminhos de escolarização, de convivência entre diferentes grupos sociais e de inclusão que não exclui.

A presença do educador surdo, segundo Nicolucci (2006, p. 70) “[...] age como referência e como modelo no processo de formação da identidade do aluno surdo, além de ser responsável pelo ensino das Libras à professora regente de classe e aos colegas ouvintes na interlocução escolar." Ou seja, a ausência desse profissional surdo dentro da escola pública dificulta o acesso à língua de sinais e aos conteúdos curriculares vigentes.

A participação da comunidade surda permite a consciência e o fortalecimento de seu papel para a educação brasileira, principalmente na busca de caminhos para a construção social de uma nova página a ser escrita por ela na política, cultura e no processo educacional.

Somente a partir dessa visão de inclusão e da participação ativa dessas forças sociais será viável a equiparação educacional surdo-ouvinte e a superação das dificuldades que certamente virão na aplicação da lei e no processo de acesso a uma educação bicultural ou multicultural. Ou seja, uma educação que valorize não apenas a língua, como pode ser interpretada a lei, mas que contribua para a construção da identidade do aluno surdo e para a presença da sua cultura dentro da escola ouvinte.

Em uma visão Bakthiniana (1995)

"na língua materna, isto é, precisamente para os membros de uma comunidade linguística dada, $\quad o$ sinal $e \quad o$ reconhecimento estão dialeticamente apagados"

$\mathrm{Ou}$ seja, os membros dessa comunidade já compreendem de tal forma os signos que estes possuem o reconhecimento e a compreensão para a vida social e linguística de cada membro. Porém "no processo de assimilação de uma nova língua estrangeira sente-se a 'sinalidade' e o reconhecimento, que não foram ainda dominados..." logo, justifica-se aqui, determinadas dificuldades dos alunos surdos ao aprender a Língua Portuguesa, pois esta é uma língua estrangeira para eles, pois possuem como língua materna a LIBRAS.

Em qualquer idioma a palavra não é utilizada de uma forma fixa, como uma palavra do dicionário, em seu contexto diário ela traz consigo significados diferenciados, sentidos ideológicos ou vivencial diferenciando as forma de compreendê-la, sabendo, ainda, que é inseparável seu 
conteúdo ideológico ou relativo a vida do seu uso prático. Tal realidade dificulta ainda mais a aprendizagem de um segundo idioma, pois este traz do primeiro a base para a compreensão e a significação construída ideológica e historicamente da língua materna.

Entendendo a língua como uma forma viva onde a significação se dará através do contexto em que está inserida, não há como negar que para aprender um novo idioma é necessário que o aprendiz tenha que vivenciálo por meio da inserção no contexto de produção e em situações concretas de enunciação. Somente desta forma, utilizando a língua de uma maneira viva nos diferentes contextos e significações em que ela se apresenta, terá uma aprendizagem concreta e eficaz, intercambiando conhecimentos e embates ideológicos, gerando assim novos conhecimentos.

A educação inclusiva, através do bilinguismo pode garantir a permanência do aluno surdo no sistema regular de ensino, desde a educação infantil até a universidade, com igualdade de oportunidades, expondo-o a um processo de ensino-aprendizagem com qualidade.

É relevante lembrar que para educar indivíduos surdos não adianta inseri-los em turmas regulares com currículos e métodos voltados para alunos ouvintes. A surdez é muito mais uma questão linguística e cultural do que propriamente ligada à deficiência. A necessidade especial do aluno surdo refere-se, principalmente, à comunicação e compreensão de como se estabelece a aquisição de conhecimentos e desenvolvimento cognitivo do indivíduo surdo.

No que tange ao currículo, para Skliar (1999)

“[...] as prioridades são aprovar um currículo que define a si mesmo em termos de conteúdo e método."

Este pesquisador considera que o sistema educacional é definido pelo grupo majoritário e, portanto, o currículo que prevalece na escola está ajustado às características do alunado ouvinte, que tem audição, ou seja, fundamenta-se em uma perspectiva auditiva de mundo.

Para propor uma política educacional adequada a um ensino de qualidade a alunos surdos é necessária uma tradução desse currículo para a língua de sinais, o que tem sido realizado apenas por pessoas ouvintes, intérpretes Libras-Língua Portuguesa, cumprindo, timidamente ainda, o disposto pelo decreto $n^{\circ} 5.626 / 2005$ que regulamenta a Lei de Libras (BRASIL, 2005).

A inclusão de alunos surdos requer mais do que mera tolerância, implica tomar uma nova postura, requer uma nova proposta pedagógica que reestruture o currículo, a metodologia de ensino, as avaliações e as 
atitudes dos educadores. Incluir, portanto, não significa somente matricular os alunos com surdez e/ ou outras necessidades educacionais especiais, mas significa oferecer ao professor e à escola o suporte necessário para sua ação pedagógica.

A educação inclusiva é a prática de inclusão de todos os alunos, independentemente de suas deficiências, em escolas e salas de aulas adequadas, de modo que haja o aprendizado do conteúdo acadêmico por eles. O desafio deste ensino é o de desenvolver uma pedagogia centrada no discente, capaz de educar a todo e qualquer aluno no ensino regular, independentemente de suas condições físicas ou origem social e cultural, com sucesso.

Um dos principais desafios enfrentados para que haja uma plena implementação da educação inclusiva referese à questão dos professores que já atuam no sistema escolar e daqueles que estão se preparando para isto; a priori, o professor precisaria encontrar modos de intervenção pedagógica ou adequar a sua prática no sentido de chegar até o modo peculiar de aprender de cada aluno, sempre respeitando suas diferenças individuais.

\section{4 - CONSIDERAÇÕES FINAIS}

O processo de inclusão de surdos nas classes regulares se depara com duas vertentes.Na primeira, o fato de que ocorrendo a inclusão nas classes regulares evita-se a discriminação. $\mathrm{Na}$ outra, observase que alguns alunos surdos possuem dificuldade em acompanhar a classe regular quando comparados com os alunos ouvintes de mesma idade cronológica.

Assim, é importante ressaltar que para haver uma educação democrática, não basta matricular alunos com deficiência em turmas regulares ou simplesmente admiti-los na escola. Uma escola inclusiva precisa ser mais do que um espaço de convivência.Deve ser o lugar onde esses alunos tenham acesso aos saberes valorizados socialmente e em condições de adquiri-los considerando-se suas diferenças cognitivas, físicas, sensoriais, sociais e culturais.

Nessa perspectiva, conclui-se que não se pode pensar a educação de surdos com soluções simplistas. Não basta que o indivíduo esteja na escola. É preciso que lhe sejam oferecidas oportunidades de construir seu saber, sua identidade e sua cultura para que não seja apenas alguém adaptado à sociedade, mas sim sujeito construtor de si mesmo e partícipe da sociedade em que vive.

\section{REFERÊNCIAS}

ARANHA, M.S.F. Inclusão social e municipalização. In: MANZINI, E.J. Educação Especial: temas atuais. Marília, SP: Unesp, 2000, p. 01-09. 
BAKHTIN, Mikhail (Volochinov). Marxismo e filosofia da linguagem. $7^{\circ}$. ed. São Paulo: HUCITEC, 1995.

BARBOSA, D.P. Intérpretes de Libras: o que pensam acerca da educação do aluno surdo.Teresina, 2010. 80f. Monografia (Licenciatura em Pedagogia) - Universidade Federal do Piauí, 2010.

BRASIL. Constituição. Constituição da Republica Federativa do Brasil. Brasília, DF: Senado, 1988.

BRASIL. Ministério da Justiça. Declaração de Salamanca e Linha de Ação sobre Necessidades Educativas Especiais. Brasília: CORDE, 1994.

BRASIL. Política Nacional de Educação Especial. Secretaria de Educação Especial, Ministério da Educação. Brasília, DF, 1994.

BRASIL. MEC/SEESP. Educar na Diversidade. Material de Formação Docente. Ministério da Educação. Secretaria de Educação Especial. 2005. Disponível em: $<$ http://portal.mec.gov.br/seesp/arquivos/pdf/e ducar\%20na\%20diversidade.pdf $>$. Acesso em: 27 maio. 2014.
BRASIL. Decreto No. 5.626 de 22 de dezembro de 2005. Brasília: Presidência da República, Casa Civil, 2005.

BRASIL. Lei de Diretrizes e Bases da Educação Nacional. $N^{\circ} 9.394$ de 20 de dezembro de 1996. Disponível em: $<$ http://www.planalto.gov.br/ccivil_03/Leis/L 9394.htm>. Acesso: 27 maio 2014.

FERREIRA, M.E.C; GUIMARÃES, M. Educação inclusiva. Rio de Janeiro, DP\&A, 2006.

GOLDFELD, M. A criança surda: linguagem e cognição numa perspectiva sóciointeracionista. São Paulo: Plexus, 1997.

LACERDA, C.B.F. Um pouco da história das diferentes abordagens na educação dos surdos. Caderno CEDES, Campinas, v. 19, n. 46, 1998.

MANTOAN, M.T.E; PRIETO, R.G; ARANTES, V.A. (Org). Inclusão escolar: Pontos e Contrapontos. São Paulo: Summus, 2006.

MOURA, M.C. O surdo: caminhos para uma nova identidade. Rio de Janeiro: REVINTER, 2000. 
NICOLUCCI, D. Educação de surdos: uma proposta de intervenção para uma escola pública. Ribeirão Preto, SP: CUML, 2006. 110 f. Dissertação (Mestrado em Educação) Centro Universitário Moura Lacerda.

PEDROSO, C.C.A. Com a palavra o surdo: aspectos do seu processo de escolarização. São Carlos, SP: UFSCAR, 2001.155f. Dissertação (Mestrado em Educação) Universidade Federal de São Carlos.

PERLIN. G.T.T; STROBEL, K. Fundamentos da educação de surdos. Florianópolis: Editora UFSC, 2006.

REILY, L. O papel da igreja nos primórdios da educação dos surdos. In. Revista Brasileira de. Educação. Rio de Janeiro maio/ ago. v. 12 n.35, 2007.

SÁ, N.R.L. Cultura, poder e educação de surdos. Manaus: Editora UFA, 2002.

SASSAKI, R.K. Inclusão: construindo uma sociedade para todos. Rio de Janeiro: WVA, 1997.

II: espaços e tempos de aprendizagem na educação de surdos. Santa Cruz do Sul: EDUNISC, 2006
SKLIAR, Carlos. Abordagens sócioantropológicas em educação especial. In: - (Org.). Educação e exclusão: abordagens sócio-antropológicas em educação especial. Porto Alegre: Mediação, 1997.

SKLIAR, C. A localização Política da educação bilíngüe para surdos. In: SKLIAR, C. (Org.), Atualidade da educação bilíngüe para surdos: interfaces entre pedagogia e lingüística 2 ed. Porto Alegre: Mediação, 1999, p.07-14.

SKLIAR, Carlos. Uma perspectiva sóciohistórica sobre a psicologia e a educação dos surdos. In: SKLIAR, C (Org) Educação \& Exclusão: abordagens sócio-antropológicas em educação especial. Porto Alegre: Mediação 2001, p.107-154.

SKLIAR, C.(Org.). A surdez: um olhar sobre as diferenças. Porto Alegre: Mediação, 2005.

THOMA, A. Educação dos surdos: dos espaços e tempos de reclusão aos espaços e tempos inclusivos. In: A invenção da surdez

WILKIPEDIA. THOMAS HOPKINS GALLAUDET Disponível em: http://pt.wikipedia.org/wiki/Thomas_Hopkins _Gallaudet acessado em 22-05-2014 